\title{
El cabildo de la iglesia Catedral de Ávila a fines de la Edad Media
}

\author{
CARMELo LuIS LOPEZ \\ UNED
}

\begin{abstract}
RESUMEN
ABSTRACT

En este trabajo se ofrece una visión global In this work, it is offered a global vision of del cabildo catedralicio de Ávila. A partir the Avila's cathedral chapter. Based on the documents about statutes and de la documentación sobre estatutos y ordenanzas del cabildo, que en su día publicó el autor, se pasa revista a todas y cada una de las personas que componen

el cabildo abulense, indicando sus competencias y obligaciones, asi como los ingresos que recibian en función de su participación en las actividades capitulares. Por último, se señalan algunas de las medidas establecidas a lo ordinances of the chapter, at the proper time published by the author, each member of the Avila's chapter is revised, pointing out their rights and duties, as well as the incomes they received according their participation in the chapter activities. Finally, several measures adopted along the years for the well functioning of the chapter, are pointed out.
\end{abstract} largo del tiempo para el buen funcionamiento del cabildo.

\section{PALABRAS CLAVE}

Iglesia. Cabildo catedralicio. Ávila. Siglos $X I I I-X V$.
KEY WORDS

Church, Cathedral Chapter, Avila, xIII-xvth Centuries.

\section{INTRODUCCIÓN}

El cabildo de la iglesia Catedral de Ávila fue estudiado por el Dr. López-Arévalo en el año 1966. Su importante obra es de consulta obligada para conocer los aspectos jurídicos del mismo; aunque fue muy amplio el periodo que eligió —siglos Xill-XIX-, utilizó numerosa documentación medieval, incluyendo en el apéndice documental nueve documentos medievales que le sirvieron de base para analizar la 
constitución del cabildo '. En el año 1973 inicia el profesor Barrios García sus estudios sobre la catedral abulense en los aspectos sociales y económicos ${ }^{2}$, proceso de investigación que culminaría con la realización de su tesis doctoral ${ }^{3}$. Más recientemente, nosotros también nos hemos ocupado del estudio del cabildo ${ }^{4}$.

El origen del cabildo como institución debe situarse en la concesión de las Constituciones de 1250 y en la Consignación de Rentas del mismo año, en que se separa la mesa episcopal, cuya cabeza es el obispo, de la mesa capitular, formada por el deán y el cabildo. Las primeras constituciones fueron las otorgadas por el Cardenal Gil Torres en Lyon el 30 de marzo de $1250^{5}$, confirmadas por el Papa Inocencio IV el 29 de agosto de $1250^{6}$, y el estatuto aprobado por el obispo don Benito el 2 de octubre de $1256^{\text {? }}$.

Para el presente trabajo utilizaremos fundamentalmente nuestra obra Estatutos y Ordenanzas de la iglesia Catedral de Ávila (1250-1510), así como algunos datos económicos para el personal subalterno del cabildo, procedentes de la Recopilación de 1513 .

A finales de la Edad Media, el cabildo estaría formado por las personas siguientes: diez dignidades (deán, arcedianos de Ávila, Arévalo, Olmedo, Bonilla y Oropesa, chantre, maestrescuela, tesorero y prior); trece canónigos ${ }^{8}$; siete porcioneros mayores o racioneros; doce porcioneros menores o mediorracioneros; un capellán mayor; veinte capellanes; doce niños de coro; cuarenta niños de «a cuarenta»; veinte servidores clérigos de las dignidades ${ }^{9}$; dos sacristanes del tesorero;

Lopez-Arevalo, J. R.: Un cabildo catedral de la Vieja Castilla. Ávila: su estructura juridica, siglos xII$x x$, Madrid, 1966

Barrios Garcla, A.: La Catedral de Avila, en la Edad Media: Estructura Socio-juridica y Económica. Caja de Ahorros y Préstamos de Ávila, Ávila, 1973.

3 Barrios Garcia, Á.: Estructuras Agrarias y de Poder en Castilla: el ejemplo de Ávila (1085-1320), Ediciones de la Universidad de Salamanca y Ediciones de la "Institución Gran Duque de Alba". Ávila, 1983-84

4 Luis Lopez, C.: Estatutos y Ordenanzas de la iglesia Catedral de Avila (1250-1512), Serie "Fuentes Históricas Abulenses", núm. 60, Ávila, 2004. Id. Libro de Estatutos de la iglesia Catedral de Ávila de 1513. Ávila, 2005.

Documento muy importante para conocer la composición del cabildo, asi como las atribuciones competencias, derechos, etc. de los beneficiados, ha sido recientemente publicado por nosotros. Vid. Luis Lopez, C.: Estatutos y Ordenanzas de la iglesia Catedral de Ávila (1250-1510). Ávila, 2004, págs. 25-40, docs. nums. 1 y 3. También ha sido publicado por: MANSILla REoyo, D.: Iglesia castellano-leonesa y curia romana en los tiempos del rey San Fernando, Madrid, 1945, págs. 344-357, Quintana PRIETO, A.: La documentación pontificia de Inocencio IV (1243-1254), vol. II, Roma, 1987, págs. 586-598; y por BARRios Garcia, Á.: Documentación de la Catedral de Avila (siglos xII-xili), Ávila, 2004, pp. 128-143, y 158-159.

6 Vid. Luis Lopez, C.: op. cit., pág. 41; Mansilla Reoyo, D., op. cit, págs. 344 y 357; Quintana PrieTO, A.: op. cit., págs. 586 y 598; y Barrios Garcia, Á. : op. cit., págs. 158-159.

Vid. LuIS LCPEZ, C : Estatutos y Ordenanzas de la iglesia Catedral de Avila (1250-1510), Ávila, 2004, págs. 42-45. Publicado también por López-Arevalo, J. R.: Un cabildo catedral de la Vieja Castilla. Ávila: su estructura juridica, siglos xil-xx, Madrid, 1966, págs. 297-303; BarRios GarClA, A.: La Catedral de Avila en la Edad Media: estructura Socio-juridica y económica, Avila, 1973, págs. 112-119; Id. BaRRios Garcia, A.: Documentación de la Catedral de Ávila (siglos xı-xili), Ávila, 2004, págs. 174-179.

* El número de canónigos en el siglo xvı debió de oscilar de 13 a 20.

y Se ha incluido entre estos servidores a los del tesorero, como dignidad, ya que los sacristanes y servidores que se relacionan a continuación lo serian para el servicio directo dei tesorero en la iglesia. 
dos servidores del tesorero; trece servidores clérigos de los canónigos; veinte familiares clérigos de las dignidades; trece familiares clérigos de los canónigos; un sochantre; un sacristán; un organista; un campanero; un pertiguero; un perrero; y una cerera. En total, aproximadamente, podemos calcular que el cabildo estaba formado a finales del siglo xv por 192 personas $^{10}$.

Sin embargo, si se considera al cabildo formado sólo por los beneficiados, entonces el número seria más reducido: diez dignidades, trece canónigos, siete porcioneros mayores o racioneros, doce porcioneros menores o mediorracioneros y un capellán mayor; formarían este cabildo en sentido estricto cuarenta y tres personas.

\section{ESTATUTOS Y ORDENANZAS SOBRE EL CLERO PRINCIPAL DEL CABILDO}

Las dignidades de la iglesia Catedral en la época medieval fueron las siguientes:

1. El deán. Era el jefe o superior del cabildo, ocupando el primer lugar de las dignidades, y entraba en su competencia resolver la mayoría de los conflictos que se suscitaran entre los miembros del cabildo, debiendo de tomar las cuentas a los mayordomos de la iglesia Catedral. Presidía los actos en la catedral en ausencia del obispo, debiendo velar para que los beneficiados y servidores de la misma cumplieran sus obligaciones, corrigiendo a los negligentes, aunque las apelaciones de sus decisiones eran resueltas por el obispo, el cual también podía decidir sobre las funciones del deán cuando éste fuera negligente en su cumplimiento ${ }^{11}$. Además, guardaba el sello del cabildo ${ }^{12}$.

2. Los arcedianos. Desde las Constituciones de 1250, habia en el cabildo abulense tres arcedianos: los de Ávila, Arévalo y Olmedo. Estos arcedianos colaboraban con los obispos en la vigilancia y correción de los abusos que cometían algunos arciprestes del obispado, ya que en periodos de sede vacante daban sin licencia letras comendaticias para que obispos foráneos ordenaran a los clérigos, usurpaban los derechos de los arcedianos al presentar clérigos al obispo para que recibieran las órdenes, nombraban clérigos para las parroquias sin licencia y no denunciaban la conducta de los clérigos concubinarios ${ }^{13}$. Hasta el final de la Edad Media no variará el número de los arcedianos.

10 No se incluyen los mayordomos, contadores, sumador, maestro de los mozos de coro, maestro cantor, y bachiller de la Gramática ya que pensamos que estos cargos los ostentaban personas que eran beneficiados de la catedral: dignidades, canónigos, racioneros c mediorracioneros.

11 Luis Lopez, C.: Estatutos y Ordenanzas de la iglesia Catedral de Ávila (1250-1512), Ávila, 2004 doc. núm. 1, pág. 29: De officio decani, capitulo I $X$. Ad decanum volumus pertinere maiordomos capituli per ipsum compelli bis in anno, capitulo redere rationem, audire lites et causas inter canonicos et porcionarios ad ipsum per querelas delatas et eas dirimere, nisi per apellationem vel per negligentiam decani ad episcopum deferantur.

1. Sobre las funciones y competencias del deán, Vid. J. R. López-Arévalo, op. cit., págs. 81-84.

13 Luis Lópz, C.: Estatutos y Ordenanzas de la iglesia Catedral de Ávila (1250-1510), Ávila, 2004 doc. núm. 1, págs. 37-38. 
Sabemos que, en 1475, don Alfonso de Fonseca, obispo de Ávila, autorizó a don Alfonso González de Valderrábano, deán de la catedral, a don Alfonso Martínez, tesorero de la misma, y a don Juan de Ribas, canónigo, para que en su nombre crearan la dignidad de arcediano de Bonilla, anexando y dotando a dicha dignidad el préstamo o préstamos en las rentas del obispado hasta 25.000 maravedíes, realizando el obispo provisión y colación canónica de dicho arcedianazgo a favor del bachiller Alfonso de Ulloa, su vicario general y racionero de la catedral, clérigo de la diócesis de Zamora, que ocuparía el último lugar en el coro entre las dignidades: "que fuese la dicha dignidad arçedianadgo postrimera de todas las otras siete dignidades de la dicha su yglesia, asy en el coro e cabildo conmo en las proçesiones e en votar e en todas las otras cosas" '4. Poco después, en 1481, el mismo obispo erigió el arcedianazgo de Oropesa, señalándole lugar y silla en el coro de la catedral, encima del maestrescuela y debajo del chantre, y lo puso a cargo de su primo el canónigo don Juan de Fonseca. Se estableció que ocuparían, después de la muerte del chantre y de don Rodrigo de Santaella, los lugares correspondientes en el coro y cabildo, detrás de los otros arcedianos que había en dicha iglesia ${ }^{15}$. En el año 1505, estos dos arcedianazgos fueron suprimidos por el abad del monasterio de Santispíritus y por el prior del monasterio de Santo Tomás de Ávila, autorizados por el Papa Julio $1{ }^{16}$.

3. El chantre. Ostentaba la jefatura del coro y era el máximo responsable de la organización de las procesiones, ordenándolas y entonando el canto, de tal forma que fueran delante los beneficiados de mayor categoría: dignidades, canónigos, racioneros y mediorracioneros. Nombraba los hebdomadarios y a las personas que debian cantar los responsos, antífonas y otros oficios; era competencia suya procurar que hubiera en el coro todo lo necesario para los oficios: libros, candelabros, etc., así como los ornamentos necesarios para los clérigos que asistian a las procesiones (capas, báculos, amitos, etc.); y debia vigilar que los miembros del cabildo vistieran las ropas adecuadas y que cumplieran las normas de aseo personal, especialmente la forma de la corona y el afeitado: "ad mandatum eius raddant barbas et coronas omnes clerici, tam de maiori choro quam de mediano" ${ }^{17}$.

4. El Tesorero. Su principal competencia era el cuidado del tesoro de la iglesia Catedral, de las arcas y depósitos en los que se guardaban los utensilios sagrados, los libros y las ropas necesarias para las funciones de dicha iglesia, estando a sus órdenes directas dos sacristanes clérigos y dos servidores, encargándose, también, de la reparación de las campanas, capas, cortinas, vestimentos, libros y ornamentos de la catedral ${ }^{18}$. Desde el año 1390 debía hacerse cargo de los frutos, rentas y posesiones de la catedral, así como de la vigilancia del

14 Ibidem, doc. núm. 71, págs. 143-146; y Lopez-Arévalo, J. R.: op. cit., págs. 310-313.

15 Ibidem, doc. núm. 86, págs. 177-179. Vid., tambièn, López-ARÉvalo, J. R., op. cit., págs. $177-179$.

16 Ibidem, doc. núm. 112, págs. 235-238. También en López-AREvalo, J. R., op.cit., págs. 325-330.

Ibidem, doc núm. 1, De officio cantoris, capitulo $X^{\circ}$, págs. 29-30.

${ }_{18}$ Ibidem, doc. núm. 1, De officio thesaurarii, capitulo X $1^{\circ}$, pp. 30-31. Vid., también, López-AREVAlo, J. R.: op. cit. págs. $87-88$. 
campanero, cerera y otros oficiales que estaban al cuidado del óleo, cera e incienso ${ }^{19}$.

5. El maestrescuela. Las principales competencias de esta dignidad eran buscar a una persona docta y preparada que enseñara Gramática a los clérigos del coro, corregir las lecciones y los libros, asi como revisar los documentos antes de que fueran sellados ${ }^{20}$. En la Recopilación de 1513 se va a precisar cómo deberia de hacer la corrección de los libros: se le encomienda como principal misión corregir todos los vicios, faltas y malos latines de todos los libros de la iglesia Catedral; tarea que debía de realizar cada tres años, de la forma siguiente: el primer año, los misales, evangeliarios y epistolarios; el segundo año, los leccionarios, dominicales y santorales de lectura; y, el tercer año, los libros de canto o cantorales. En el caso de que no estuviera presente esta dignidad, no residiendo ni ganando en ella sus prebendas, debería el cabildo de elegir, el día de San Cebrián, un lugarteniente de maestrescuela para que realizara las funciones de tal dignidad.

6. El lugarteniente de deán. En las Constituciones de 1250 se establecía que, si se ausentaba el deán, debía de dejar un vicario idóneo en su puesto: "cum emundum abesse contigerint, vicarium ydoneum derelinquat $"{ }^{21}$. No volvemos a tener noticia de este cargo en algún estatuto $u$ ordenanza hasta la reglamentación de esta dignidad en el año 1510, porque quería el deán nombrar él a su sustituto en contra de los intereses del resto de los capitulares, por lo que debian ser frecuentes los pleitos, debates y diferencias. La solución a la que finalmente se llegó, parece ser que fue favorable a la postura del cabildo, ya que se establece un orden riguroso sobre la persona que debia de desempeñar el cargo: recaería en lo sucesivo en el que ostentara la presidencia del coro en ausencia del deán, es decir, en primer lugar, la más antigua de las dignidades; en segundo lugar, en defecto de tal dignidad, en el más antiguo de los canónigos; en tercer lugar, en ausencia de éstos, en el racionero más antiguo; y, por último, si no asistía dignidad, canónigo o racionero, en el más antiguo de los mediorracioneros. Al mismo tiempo se especifica en el estatuto que el sodeán o lugarteniente de deán sólo debia entender en los tres casos siguientes: cuando se hiciera Sínodo General en el obispado, cuando el señor obispo con el cabildo, o el cabildo sólo, hicieran u ordenaran algún estatuto o cuando el cabildo hubiera de otorgar cartas de censos o censos enfitéuticos; en cada uno de estos tres casos, si no estaba el deán presente en el obispado, se debía nombrar lugarteniente de deán, debiendo jurar, antes de ser nombrado, que guardaría el estatuto ${ }^{22}$. Indudablemente, la aprobación del citado estatuto suponia un triunfo del cabildo sobre el deán al reducir la posibilidad de que, nombrando el deán para ese cargo a persona de su confianza, pudiera contar con dos votos seguros en el cabildo y, sobre todo, entre las dignidades, que eran los cargos más importantes del cabildo.

\footnotetext{
Vid. Luis Lopez, C.: op. cit., Ávila, 2004, doc. núm. 8, págs. 51-54.

Ibidem, doc núm. 1, De officio magistri scolarum, capitulo XII', pág. 31.

1 Ibidem doc núm. 1, De oficcio decani, capitulo $/ X^{\circ}$, pág. 29.

22 Ibidem, doc. núm. 120, págs. 245-247.
} 
7. El Prior. La primera noticia de un prior en la catedral de Ávila aparece en el año 1176, en que figura como testigo prior Martinus Michaeli; poco después, en 1181, se relaciona a Martinus, prior ecclesie Sancti Salvatoris ${ }^{23}$; aunque pensamos que este prior es el deán de la catedral, ya que, a veces, el deán era designado también con dicho nombre.

Esta dignidad, considerada como el primero de los canónigos, fue creada en 1487 por el Papa Inocencio VIII, nombrando para dicho cargo a Alfonso Velasco, medio porcionero y notario apostólico de la iglesia Catedral de Ávila ${ }^{24}$. Dicha dignidad fue suprimida en 1505 por el prior del monasterio de Santo Tomás de Ávila y el abad del monasterio de Santispíritus de Ávila, comisionados por el Papa Julio $1{ }^{25}$. Sin embargo, a pesar de esta supresión, volvió a existir en la catedral este cargo o no se había llevado a efecto dicha supresión, porque en el año 1509 figura en la iglesia Catedral de Ávila, cuando se está realizando un estatuto, «don Ruy Garcia Manso, prior en la dicha iglesia e provisor en la çibdad e obispado de Ávila por el muy reverendo e muy magnífico señor don Alonso Carrillo de Albornoz, obispo de Ávila" ${ }^{26}$. En el año 1513 continúa la misma persona desempeñado el cargo de prior, incluido entre las dignidades de la catedral.

8. Los Canónigos. Relacionado con los canónigos no hay ningún estatuto que, de forma exclusiva, se refiera a ellos, excepto en la distribución de las prebendas, como a otros beneficiados de la iglesia Catedral. Como ya hemos dicho, en la Edad Media había en la catedral 13 canónigos, aunque en el siglo XVI se aumentó el número hasta 20. Los canónigos de oficio (doctoral, penitenciario, magistral y lectoral) no se crean en la catedral abulense hasta el siglo XVI.

9. Provisores generales y provisores del Obispado. En el año 1469 el deán y cabildo nombraron a dos provisores oficiales generales del obispado que eran canónigos; y provisores en las ocho zonas en que estaba dividido el obispado: Ávila y Pinares, Arévalo, Olmedo, Madrigal, Bonilla de la Sierra, Piedrahíta, Arenas y Colmenar (Mombeltrán) con sus vicarías, y Oropesa y Castil de Bayuela; éstos provisores eran canónigos y arcedianos, aunque no figuran en el documento las competencias de los mismos ${ }^{27}$.

Ingresos de los beneficiados. No sabemos con seguridad los ingresos de los prebendados, al final de la Edad Media. La parte más importante del salario de los beneficiados era la renta de los préstamos que se unian a los distintos cargos del cabildo, cuya cuantía variaba en función de la importancia de cada uno de dichos beneficiados.

23 Baririos Garcia, A.: Documentos de la Catedral de Ávila (siglos XI1-XII). Ávila, 2004, págs. 44 y 52.

24 LuIs López, C.: op. cit., doc. núm. 94, págs. 188-192. Vid., tambièn López-AREvalo, J. R.: op. cit. págs. $315-322$.

26 Ibidem, doc. num. 112, págs. 235-238. Y LoPez-AREvalo, J. R.: op. cit págs. 325-330.

26 lbidem, doc. núm. 118, págs. 241-243.

27 Ibidem, doc núm. 54, pág. 127. 
En las Constituciones de Inocencio IV, de 1250, las cantidades a percibir eran las siguientes: el deán, 150 maravedíes, como dignidad, y 50 maravedíes como canónigo, en total 200 maravedies ${ }^{28}$; el arcediano de Ávila, 130 maravedies como dignidad y 50 maravedies como canónigo, en total 180 maravedies ${ }^{29}$; los arcedianos de Arévalo y de Olmedo, el chantre, el tesorero y el maestrescuela, cada uno, 100 maravedíes como dignidades y 50 maravedíes como canónigos ${ }^{30}$; los canónigos, cada uno, 50 maravedies ${ }^{31}$; los porcioneros mayores, cada uno, 26 maravedíes, y los porcioneros menores, cada uno 13 maravedies ${ }^{32}$. La relación entre dichos salarios sería, aproximadamente, la siguiente: el deán 12 veces más que el porcionero menor; el arcediano de Ávila, 10 veces; los arcedianos de Arévalo, OImedo, chantre, tesorero y maestrescuela, 8 ; y los canónigos, 2 veces ${ }^{33}$.

En el año 1454 los canónigos, prebendados y porcioneros tenían de salario 15.000 maravedies, los mediorracioneros tendrian la mitad, es decir, 7.500 maravedies ${ }^{34}$. Aplicando una proporción similiar a la anterior, el salario de los arcedianos debería ser de 75.000 maravedies, y el del deán, 90.000 maravedies ${ }^{35}$.

En el último cuarto del siglo XV no conocemos nada más que un dato, que es el préstamo que, en el año 1475, el obispo don Alonso de Fonseca unió a la dignidad de arcediano de Bonilla que fue de 25.000 maravedies, aunque no nos sirve para el cálculo del sueldo de los arcedianos, ya que era el de menor importancia y dicha cantidad no era a costa del cabildo sino del obispado, y sabemos que dicho arcediano siguió percibiendo el sueldo de racionero de la catedral, además de los citados maravedies ${ }^{36}$.

Si tomamos como base el reparto más cercano que conocemos al final de la Edad Media, debemos referirnos al de maravedies, granos, gallinas y vino del año $1558^{37}$. Nos servirá el dato de los maravedies del repartimiento del residuo. De

28 Ibidem, pág. 26: "Quod decanus abulensis, qui secundum consuetudinem eiusdem ecclesie ab episcopo et canonicis est communiter eligendus, per provisionem episcopi habeat in prestimoniis $\mathrm{CL}^{\mathrm{a}} \mathrm{mo}$ rabetinos usualis monete, preter solitas distributiones, et $L$ morabetinos, quos debet sicut alii canonici ratione percipere canonie".

29 Ibidem, pág. 27: "Archidiaconus civitatis habeat in prestimoniis $C$ et $X X X{ }^{a}$ morabetinos, preter solitas distributiones, et $L^{a}$ morabetinos quos debet sicut alii canonici rationes percipere canonie".

30 Ibidem. pág. 27: "Arevalensis et Uimetensis archidiaconi, cantor, thesaurarius, magister scolarum, quilibet eorum habeat in prestimoniis $C$ morabetinos, preter solitas distributiones, et $L^{a}$ morabetinos quos debet sicut alii canonici ratione percipere canonie".

${ }_{31}$ Ibidem, pág. 27: "Canonicus habeat in prestimonis $\mathrm{L}^{\mathrm{a}}$ morabetinos, preter solitas distributiones's.

32 Ibidem, pág. 27: Porcionarius habeat XXVI morabetinos. In minori beneficio constitutus XIII morabetinos, preter solitas distributiones. In hac estimatione computatis prestimoniis que nunc habent".

33 Para el cálculo hemos tenido en cuenta el salario del deán y de los arcedianos sin contar lo que ganaban como canónigos

34 LuIS López, C. op. cit., doc. núm. 32, págs. 85-87.

35 Para conocer la capacidad económica de estos salarios indicaremos que ese mismo año una fanega de trigo valía 75 maravedies, o una cántara de vino 33,5 maravedies. Vid. LUIS LOPEZ, C.: La Comunidad de Villa y Tierra de Piedrahita en el tránsito de la Edad Media a la Moderna. Ávila, 1987, págs. 414-415.

${ }^{36}$ LUIS LoPEZ, C.: Estatutos y Ordenanzas, op. cit., doc. num. 71, págs. 143-146.

37 LOPEZ-AREVAlo, J. R., op. cit., págs. 198-199. 
acuerdo con él, recibieron los beneficiados del Cabildo lo siguiente: el deán, 218.084 maravedies; la mayoría de las dignidades, 163.563 maravedíes; los canónigos, 109.042 maravedies; los que podrían ser racioneros, 54.521 maravedies; y los mediorracioneros, $27.260,5$ maravedies. La relación es exacta: al deán se le repartió 8 veces más que al mediorracionero; a los arcedianos 6 veces; a los canónigos 4 veces; y a los racioneros, 2 veces.

Podemos calcular que el salario del deán al final de la Edad Media, aproximadamente, sería de 150.000 maravedies; el de los arcedianos de Ávila, Olmedo y Arévalo, y otras dignidades 120.000 maravedies; los canónigos, 80.000 maravedies; los racioneros, 50.000 maravedies; y los mediorracioneros, 25.000 maravedíes. Aparte de esto estarían los ingresos por horas, aniversarios, pitanzas (manuales, ordinarias y extraordinarias), préstamos de cuaresma, maitines, cornado y residuos que, como hemos visto, algunos años podían alcanzar cantidades muy elevadas.

Hay que tener en cuenta que con estos ingresos las dignidades debian mantener a cuatro familias, y los canónigos a dos. Además debían pagar los salarios de los servidores y criados que tenían para poder vivir con el lujo y boato que se les exigía, no sólo en sus personas sino también en sus domicilios, cuyo exponente máximo sería el deán que residía en amplias mansiones capaces de albergar a sus numerosos servidores.

Para dar una idea del poder adquisitivo de estos salarios, bastaría con citar algunos precios de productos agrarios o ganaderos de finales del siglo XV. Para ello hemos calculado la media de los precios que conocemos en la última década del siglo XV. Por ejemplo, una fanega de trigo valía 92 maravedies; una cántara de vino, 37 maravedies; un toro, 2.150 maravedies; y un carnero, 200 maravedíes $^{38}$.

Indudablemente, fueron muy elevados los ingresos del cabildo catedralicio en la Edad Media y también lo fueron los de los distintos beneficiados, pero no sería justo si no hiciéramos constar que dichos ingresos hicieron posible la realización de la extraordinaria labor desarrollada por el cabildo catedralicio abulense en obras sociales y de caridad, creando fundaciones para proteger a los desamparados y desvalidos, financiando o contribuyendo al sostenimiento de hospitales y centros asistenciales para pobres, ancianos y niños abandonados, impulsando la creación de centros docentes y colaborando con los obispos en la elevación del nivel cultural de los clérigos y la defensa a ultranza de la dignidad sacerdotal y del estado eclesiástico, así como para la formación de un importante legado documental y artístico ${ }^{39}$.

39 Vid. Luis López, C.: La Comunidad de Villa y Tierra de Piedrahita en el tránsito de la Edad Media a la Moderna. Ávila, 1987, págs 414-417.

39 Vid. Sanchez Sanchez, A.: La Beneticencia en Ávila. Actividades hospitalarias del Cabildo Catedralicio (siglos Xvi-XIX). Ávila, 2000, 500 págs. 
Como disposiciones generales que afectaban al personal dirigente del cabildo, dignidades y canónigos, es decir, a todo el personal principal del cabildo, destacaremos las siguientes:

1. ${ }^{a}$ Forma de nombramiento. Se establecía que el obispo nombraba, cuando quedaba vacante el puesto, a las personas que habian de ocupar los cargos principales del cabildo, es decir, a las dignidades, incluida entre éstas la primera de ellas, es decir, a la persona que ostentaba el cargo de deán. Parece ser que estaba derogada la disposición de la Constitución de Inocencio IV que establecía que el deán de la catedral fuera nombrado por el obispo y los canónigos: "quod decanus Abulensis, qui secundum consuetudinem eiusdem ecclesie ab espiscopo et canonicis eligendus ${ }^{40}$. Sin embargo, el nombramiento de canónigos correspondía al obispo, deán y cabildo.

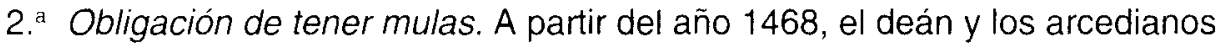
debian de tener tres cabalgaduras de silla; las otras dignidades, dos cabalgaduras; y los canónigos, racioneros y mediorracioneros, una cabalgadura. Si no cumplían este estatuto perdian el derecho a los repartos que se hacian de cebada, procedente de los pagos de rentas a la mesa capitular ${ }^{41}$.

3. Exigencia a las dignidades de que tuvieran como compañía a escuderos y capellanes. El deán y arcedianos debían llevar dos escuderos o capellanes, siempre que no fueran éstos de los del número de la catedral, que los acompañasen para que no fueran solos, tanto en la ciudad como por los caminos; el resto de las dignidades, uno. Además, los beneficiados podian tener como familiares a clérigos beneficiados en el obispado: las dignidades, dos clérigos; y los canónigos, uno ${ }^{42}$.

4. ${ }^{\text {a }}$ Medidas de prestigio personal para las dignidades y categoria de cada una de ellas. Por ejemplo, no podían ir solos ni a pie por la ciudad. El deán, por supuesto, era el jefe del cabildo y, por consiguiente, la primera de las dignidades. La siguiente de las dignidades en importancia parece ser que era el arcediano de Ávila, ya que se establecia que, para que la iglesia de Ávila fuera mejor servida y honrada, el obispo debía de decir la misa mayor en las tres Pascuas del año (Navidad, Resurrección y Espíritu Santo), acompañado por el deán en el Evangelio y por el arcediano de Ávila en la Epistola. En el caso de que no estuviera el obispo, debia decir las misas el deán o la dignidad más antigua del cabildo, al que acompañarían los canónigos o racioneros que designara ei presidente del cabildo.

5. abligación de residir en Ávila. Los beneficiados debian tener "casa puesta" en la ciudad, ya que, si no cumplian lo ordenado, no podían disfrutar del privilegio de los escusados ${ }^{43}$.

40) Vid. LuIS Lopez, C.: Estatutos y Ordenanzas de la iglesia Catedral de Ávila (1250-1510), Ávila, 2004, pág. 26.

41 Ibidem, docs núms. 50 y 92 , págs. $122-124$ y $183-185$.

4: Ibidem, doc. núm. 92, pp. 183-185.

4.3 Ibidem. p. 124: "Otrosy, que qualquier benefiçiado de la dicha iglesia que no toviese casa sobre sý non lieve nin aya parte de los escusados" 


\section{ESTATUTOS Y ORDENANZAS SOBRE EL PERSONAL SUBALTERNO DE LA CATEDRAL}

Son numerosos los estatutos y ordenanzas que se dedican a establecer minuciosamente las obligaciones, deberes y derechos del personal subalterno de la catedral. Entre ellos destacaremos los siguientes:

1. ${ }^{\text {a }}$ Mayordomo de las rentas de la iglesia Catedral y receptor o mayordomo de las rentas de la fábrica de la catedral. Había dos mayordomos de la mesa y fábrica de la catedral, nombrados por el obispo, deán y cabildo. Tenían que ver y visitar todas las obras de la iglesia, recaudar las rentas de la fábrica y pagar los salarios de los oficiales de la misma; y ambos, juntamente, debian encargarse de comprar la cera, aceite, pábilo e incienso necesarios para el culto. Estos dos mayordomos no podian arrendar por si o por persona interpuesta las rentas del cabildo o de la fábrica. Estaban obligados a depositar el dinero de su mayordomía en un arca que debía de estar en el sagrario o en el armario del cabildo con dos llaves distintas, una de ellas en poder de una dignidad, y la otra en manos de un canónigo. Podían ser mayordomos las dignidades, canónigos, racioneros y mediorracioneros de la catedral, pero siempre que desempeñaran el cargo personalmente, dando fianzas suficientes y teniendo que jurar que usarían bien y fielmente dicho oficio ${ }^{44}$.

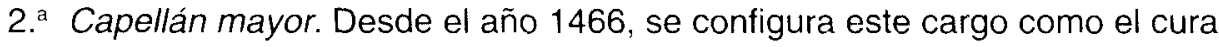
o rector de la iglesia, teniendo como principal misión la administración de los sacramentos en la catedral a las personas de la ciudad y del obispado que se lo pidieran, o fuera costumbre. Por consiguiente, como cura de la iglesia, debía velar porque el Santísimo Sacramento estuviera en el altar mayor en dos o tres formas para los enfermos en su custodia de plata y con corporales limpios, puesto en la otra custodia de marfil que estaba en las andas del altar mayor con sus llaves, renovándolo de ocho en ocho dias, aunque este periodo será posteriormente ampliado, debiendo renovarlo cada quince días. También se le encomendaba el inicio de los rezos de todas las horas canónicas (maitines, laudes, prima, tercia, sexta, nona, visperas y completas) y las horas de la Virgen y de los finados, cuando las hubiera. Asimismo, era competencia suya decir los capitulos y oraciones, echar las bendiciones y perdones, bendecir el agua, incensar el altar mayor los dias y fiestas en que era preceptivo, administrar los santos sacramentos a los feligreses, parroquianos, beneficiados y familiares de la catedral e ir con los capellanes de la iglesia catedral a por el cuerpo de las personas que hubieran de ser enterradas en la catedral ${ }^{45}$. El salario del capellán mayor, como racionero de la catedral, debería ser aproximadamente de 50.000 maravedies al año.

3. ${ }^{\text {a }}$ Capellanes de la iglesia catedral. En el año 1402 se aumenta el número de capellanes perpetuos de seis a ocho ${ }^{46}$. Pero a mediados del siglo se establece que

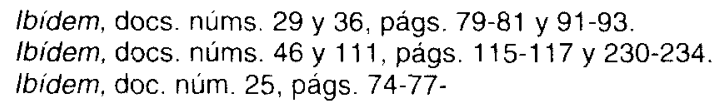


en la catedral hubiera, como mínimo, veinte capellanes. Tenían como privilegio el no ser obligados a residir personalmente en otros beneficios que tuvieran, y a administrar ellos mismos las rentas de sus capellanías. Los altares y capillas que tenian capellanes eran los siguientes: San Ildefonso, San Segundo, San Pedro, San Blas (2 capellanes), Santa Catalina (2 capellanes), Santa María de la Transfixión (2), La Transfixión, Santa Maria de Tras el Coro, San Esteban, San Nicolás, San Juan, San Miguel, San Pedro ad vincula, Las Vírgenes, San Andrés, San Dionís y San Antonio. Los capellanes debian decir obligatoriamente las misas de Santo Toribio, de San Gregorio, de San Andrés, las del altar de Las Vírgenes, las de Nuño del González del Águila, arcediano de Ávila, en el altar de San Segundo, las del chantre Juan Gutiérrez de Vayas en el altar de Nuestra Señora de Tras el Coro, y las de don Alonso González de Valderrábano, déan que habia sido de la catedral y arcediano de Olmedo, en el altar de San Ildefonso. Figura en la ordenanza la forma en que ganaban las distribuciones en las distintas horas y las pitanzas que correspondian a los semaneros del altar mayor ${ }^{4}$. En la Recopilación de 1513 figura que recibian los veinte capellanes de salario al año 90.000 maravedies del cabildo, 15.000 de la fábrica de la iglesia catedral y otros 3.500 maravedíes por determinadas misas que tenian obligatoriamente que decir; por tanto, el salario de los capellanes, independientemente de otros servicios, horas y pitanzas, era de 108.500 maravedies anuales.

4. Sochantre. Debía entonar todas las horas litúrgicas, situándose entre el facistol mayor y la silla del obispo, y estaba obligado a hacer la matrícula de los semaneros de misa, evangelio y epistola, y cambiar a este personal del cabildo todas las semanas del año ${ }^{48}$, así como organizar todas las procesiones, las pitanzas y las sepulturas, ordenando quién debía hacerlas. El salario que recibía era equivalente a una media ración (aproximadamente 25.000 maravedíes al año), además de las rentas de Brieva y de Rinconada, asi como los derechos correspondientes en los distintos oficios en los que intervenía.

5. a Sacristán. La principal competencia de este cargo era la de guardar el tesoro (oro, plata, libros, lienzos, ornamentos, etc.), conforme a un inventario que debía de estar en poder del mayordomo y controlado por el presidente del cabildo. Además, se le señalaban, entre otras, las siguientes tareas: abrir las puertas de la catedral a la hora de maitines, así como la puerta del coro, y cerrarlas al ponerse el sol, durmiendo en la iglesia Catedral para guardarla; tener provistas de agua bendita las pilas de la iglesia y la pila bautismal; ayudar a la misa del alba; decir el invitatorio de las fiestas de nueve lecciones, de ferial, la primera lección y el tercer responso; tener lumbre en la lámpara mayor durante el dia y la noche; elevar la cruz a vísperas, incensar en las fiestas solemnes, domingos, fiestas dobles y en las 16 ó 18 fiestas principales, aderezar los altares y dar las capas a los cantores; tener limpia la igiesia, preparar los túmulos en las misas de funeral y tener prepara-

47 Ibidem, doc. núm. 95, págs. 193-215.

48 Ibídem, doc. núm. 95, pág. 193-215. 
dos los óleos, alfombras, crismas, pan y vino para las misas. En 1513, recibía de los ingresos del cabildo catedralicio de salario 15.000 maravedíes, además de los derechos que le correspondían en los oficios que se realizaran en la catedral.

6. Maestros cantores. En 1465 se contrata a un cantor, obligándose éste a dar una lección por la mañana y otra por la tarde todos los días no festivos y a enseñar contrapunto y teoría del canto a los mozos de coro. Recibía de salario al año 6.000 maravedies y 20 fanegas de trigo ${ }^{49}$. En 1487, se creó el cargo de maestro cantor de la catedral, que debía cantar todas las pascuas y fiestas principales, en las 16 fiestas de la iglesia de Ávila, enseñar a cuatro niños de coro y a dar lecciones de canto llano, canto de órgano y contrapunto ${ }^{50}$.

7. Organista. Se establecía de forma pormenorizada cómo y qué órganos debía de tocar en los distintos días: los órganos mayores en las Pascuas y en las 18 fiestas; los órganos medianos en los días de los Apóstoles y en las advocaciones de la iglesia; y los órganos pequeños el resto de los dias de la Virgen, los otros dias solemnes y en los sábados. El salario de este cargo era de 12.000 maravedies y 30 fanegas de trigo.

8. ${ }^{a}$ Maestro de los mozos de coro. Tenía que enseñar a leer y cantar a los mozos del coro durante una hora cada día, asi como a leer las calendas y decirlas en el coro. El salario de este maestro era de 5.000 maravedíes anuales.

9. ${ }^{a}$ Bachiller de la Gramática. Creado el cargo en 1495, tenía el privilegio del monopolio de la enseñanza de la Gramática en Ávila y su obispado, excepto en Madrigal ${ }^{51}$.

10. ${ }^{\text {a }}$ Pertiguero. El pertiguero era un senvidor especial del cabildo y la principal obligación de este cargo era la de realizar las citaciones de cualquier persona que debiera comparecer ante el obispo, provisores, vicarios y jueces eclesiásticos. Además, debia acompañar al cabildo en todas las procesiones, estar en la misa los domingos, fiestas de la Virgen, fiestas de los Apóstoles, de los Cuatro Doctores, de los Evangelistas y las 18 fiestas principales; ir con los asistentes a la epístola y evangelio y a dar la paz al coro; guardar la puerta del cabildo mientras que estuvieran reunidos los capitulares; y poner en subasta las rentas del cabildo ${ }^{52}$. En el año 1466, recibía de salario 1.500 maravedies y 30 fanegas de trigo, asi como diversas cantidades cuando tomaban posesión las dignidades, canónigos, racioneros y mediorracioneros, o por los ascensos que consiguieran los distintos beneficiados $^{53}$.

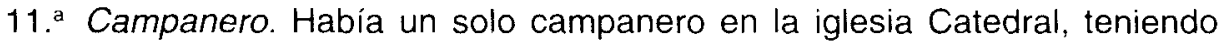
como principal función la de tocar bien las campanas (a maitines, a laudes, a prima,

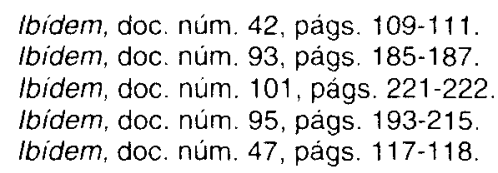


a tercia, a sexta, a nona, a vísperas, y a completas, a la misa del alba, a las procesiones y a los toques especiales de difuntos, avemaría y en tiempo de entredicho) ${ }^{54}$. El salario de este cargo capitular era de 9.000 maravedies, 45 fanegas de pan y los derechos que le correspondian por tocar las campanas en los entierros.

12. ${ }^{a}$ Mozos de coro. En la iglesia Catedral había doce mozos de coro que debían saber leer y cantar bien, dándoles el cabildo ropas de paño y del color que pareciera al cabildo, teniendo que residir estos mozos durante las distintas horas litúrgicas en la iglesia.

Asimismo, tenia la catedral otros cuarenta mozos de coro, que se llamaban los "mozos de a cuarenta», que servian en la iglesia con sus sobrepellices y estaban a las órdenes del sochantre debiendo ir vestidos con las lobas o ropas algo largas, pagando a cada uno de salario un real.

13. ${ }^{a}$ El perrero. Las funciones del perrero eran las siguientes: tocar o tañer la "señalera" (campana interior que avisaba a los beneficiados y personal del cabildo), echar de la iglesia a los perros, ir delante de la cruz en las procesiones, echando a los perros y otros animales de los sitios por donde habían de pasar, así como apartando a las personas que entorpecieran su marcha. En la Recopilación de 1513, figura que recibía como salario 600 maravedies al año, doce fanegas de pan, un capuz, un sayo, un jubón de fustán, unas calzas del paño del capuz, una camisa, una caperuza y un par de zapatos.

14. ${ }^{\text {a }}$ La cerera. Se encargaba de regar y barrer la iglesia, debiendo de tener provisión de agua y de vino para decir las misas. El salario de la cerera era de 1.000 maravedíes al año, una saya, y cuatro fanegas de trigo. Recibia, además, 150 maravedíes al mes y doce ducados al año para los gastos de la oblación.

\section{ESTATUTOS Y ORDENANZAS SOBRE LOS BENEFICIADOS EN GENERAL}

Hay numerosos estatutos y ordenanzas que se dedicaban a reglamentar, minuciosamente, los derechos, normas de comportamiento y rentas de los beneficiados en general. Destacaremos las siguientes medidas.

1. a Situación en el coro de los beneficiados. Los beneficiados eran los únicos que podían ocupar sitio en los bancos situados en el coro, durante los oficios o cuando hubiera sermón. La única persona que podia tener silla en el coro durante las horas litúrgicas o en los sermones era el obispo de Ávila. Los caballeros y principales personajes de la ciudad podían introducir sillas para sentarse, pero fuera del coro y siempre que no impidieran al preste y a sus ministros decir la misa $u$ otros oficios del culto.

54 Ibidem, doc. núm. 95, págs. 193-215. 
2. Normas sobre la honestidad de los beneficiados en los trajes y vestidos. En el año 1480 se dictan estrictas normas de honestidad en trajes y vestidos. Se les obligaba a llevar los cabellos redondos sin coleta; tener las coronas correctas y abiertas, a juicio del presidente del cabildo; no podian vestir seda de color ni prieto, excepto raso negro sin labores en jubón y en sayo; no se les autorizaba a llevar en la iglesia manga de jubón; se les prohibía vestir mantos abiertos por delante o por los lados hasta el suelo, debiendo ser los dichos mantos, largos, talares, con sus cuellos altos que cubrieran el collar del jubón y llegaran hasta tocar el suelo; no podian calzar zapatos blancos ni colorados ni borceguies, descubierto el pie, sin alcorques ni chinelas, salvo todo prieto; no se les permitía vestir grana colorada encendida en la ropa ni en el bonete ni en manto ni sayo; y, por último, se les ordenaba que no rezaran uno con otro solos en el coro durante las horas ${ }^{55}$.

3. ${ }^{\text {a }}$ Forma de nombramiento de los beneficiados. Se disponía que los canónigos, racioneros y mediorracioneros debían ser nombrados por el obispo, deán y cabildo, juntamente. La entrega de las posesiones del obispado, cuando estuviera vacante la dignidad obispal, así como las correspondientes al deanazgo, dignidades, canonjías, raciones y mediasrraciones, correspondía a los señores deán y cabildo.

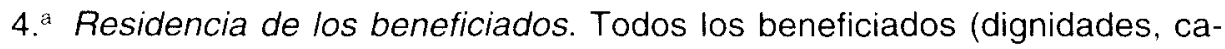
nónigos, racioneros y mediorracioneros) debian hacer una residencia, para poder disfrutar enteramente de las prebendas: de diez meses para los que tomaran posesión de nuevo, y de cuatro meses para los que ya estuvieran nombrados ${ }^{56}$.

$5 .^{a}$ Ingresos de los beneficiados que hubieran hecho la residencia. En primer lugar, las horas que podriamos llamar normales, en que cada beneficiado que tuviera ración entera (dignidades, canónigos y racioneros) cobraban lo siguiente: a maitines, 12 maravedies; a prima, el día solemne, doble o domingo, 1 maravedí, y en la denominada "forçada" 3 maravedíes más por ración; a tercia, 3 maravedíes; a sexta, 1 maravedi; a nona, 1 maravedí; y a vísperas y completas, 4 maravedies. Es decir, por este concepto todo beneficiado con ración entera cobraria cada día, si asistia a todas las horas, 22 maravedíes. El mediorracionero podría obtener por este concepto 11 maravedies diarios.

Las 16 ó 18 fiestas principales de la iglesia catedral eran las siguientes: San Miguel, Todos Santos, la Natividad de Cristo, la Circuncisión, la Epifania, la Purificación de la Virgen que es la Candelaria, la Pascua de Resurrección, la Ascensión, la Pascua del Espíritu Santo, la fiesta de La Trinidad, San Juan Bautista, San Pedro y San Pablo, Santiago, la Transfiguración, Santa Maria de Agosto y Santa María de Septiembre. Se incluyen, a veces, como fiestas principales las festividades del Corpus Christi y de San Vicente y sus hermanas. En estas fiestas los beneficiados, de forma solemne, llevaban capas de seda a la procesión por la claustra, 
mientras tañian todas las campanas, mayores y menores, y los órganos mayores, hasta entrar en el coro de las horas con su procesión, debiendo estar dichos beneficiados en sus asientos del coro hasta que pasaran la cruz, el preste, el diácono y subdiácono para dirigirse posteriormente al altar, recibiendo cada beneficiado de ración entera sesenta maravedies. Es decir, aproximadamente 1.080 maravedíes al año ${ }^{57}$.

Desde el año 1372, para dar mayor esplendor a estas fiestas, los clérigos del cabildo de San Benito, que agrupaba a los de las iglesias de la ciudad de Ávila, acordaron que irían a la catedral, para asistir a las procesiones con las cruces y crucifijos de sus parroquias, tres clérigos de San Vicente, dos clérigos de las iglesias de San Pedro y de San Juan, y uno de las otras iglesias, que eran las de Santo Tomé, La Trinidad, Santiago, San Andrés y San Martín. También acudirian cuando se hicieran procesiones especiales, como, por ejemplo, en rogativas por la salud y vida de los reyes o por la paz del reino ${ }^{58}$.

En las cinco procesiones principales, que eran el día de Navidad, el Domingo de Ramos, el primer dia de la Pascua del Espíritu Santo, el día del Corpus Christi y el día de la Transfiguración, se pagaba por cada prebenda un real.

Otros ingresos importantes por estos conceptos de pitanzas y horas los constituian los procedentes de las llamadas pitanzas manuales o mayores. Cada beneficiado de ración entera recibía en las distintas fiestas religiosas lo siguiente: San Miguel, 100 maravedies; la Vigilia de San Vicente, 100 maravedies; el Dia de San Vicente, 100 maravedies; San Simón y San Judas, 25 maravedies; Todos los Santos, 200 maravedies; Día de los Finados, a la procesión, 100 maravedies; San Andrés, 25 maravedíes; la Concepción de Nuestra Señora, 100 maravedíes; Santa María de la O, 100 maravedies; Vigilia de Santo Tomé, a la procesión, 100 maravedies; Día de Santo Tomé, a la procesión, 150 maravedies; maitines de Navidad, 250 maravedies; misa de tercia, 250 maravedies; San Esteban, 100 maravedies; San Juan Evangelista, 100 maravedies; Inocentes, 100 maravedies; Circuncisión, 100 maravedíes; Epifanía, 100 maravedies; San Sebastián, 100 maravedies; la Purificación de Nuestra Señora, 100 maravedies; la Transfixión de Nuestra Señora, 100 maravedies; Santa María de Marzo, 100 maravedies; Domingo de Ramos, 100 maravedies; el Mandato, 50 maravedies; maitines de Resurrección, 50 maravedies; Pascua de Resurrección, 150 maravedies; San Marcos, letanías mayores, 100 maravedies; San Marcos, procesión, 100 maravedies: Lunes de las Letanías, 100 maravedies; martes siguiente, 100 maravedies; miércoles siguiente, 100 maravedies; San Segundo, procesión a Santa Lucia, 100 maravedíes; Día de la Ascensión, 100 maravedíes; Santispíritus, a maitines, 150 maravedies; Día de Santispíritus, 150 maravedies; Día de la Trinidad, 150 maravedies; Corpus Christi, 150 maravedíes; San Marcos, 100 maravedies; San Juan Bautista, 100 maravedies; San Pedro, 100 maravedies; Santiago, 100 maravedies:

58 lbidem, doc núm. 5, págs. 46-48. 
Transfiguración del Señor, 150 maravedies; Santa María de Agosto, 150 maravedies; y Santa María de Septiembre, 100 maravedies. En total, cada prebendado de ración entera tendria, como ingresos al año por este concepto, 4.750 maravedíes y el mediorracionero, 2.375 maravedíes ${ }^{59}$.

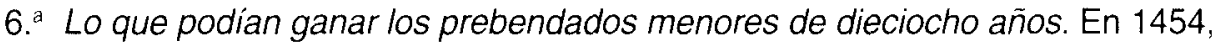
se dispuso que estos beneficiados se situaran en el coro debajo de los otros, aunque su beneficio fuera de mayor categoría, no estando autorizados a subir a la silla que les correspondiera hasta que no cumplieran los dieciocho años de edad ${ }^{60}$. Tampoco podian recibir frutos, pan, vino, aves y residuos de la mesa capitular, debiendo dedicarse a aprender bien a leer, a escribir y a cantar en el coro ${ }^{61}$. Las ordenanzas fueron confirmadas por el Papa Julio II el 4 de noviembre de $1510^{62}$.

7. ${ }^{a}$ Salarios de los prebendados en casos especiales. Se les protegía contra los abusos judiciales, tanto cuando eran citados por juez competente para presentarse ante los tribunales eclesiásticos por pleito sobre su prebenda o prebendas después de haberlas poseído, quieta y pacíficamente, por espacio de tres años, en cuyo caso, debian ser contados como presentes y se les entregaban las rentas de las mismas ${ }^{63}$, como cuando eran desterrados injustamente por la justicia eclesiástica o seglar, siendo también contados en su prebenda, excepto maitines, el cornado y el préstamo de cuaresma, reservando al cabildo la competencia de declarar o decidir cuándo el destierro era justo 0 injusto ${ }^{64}$.

Pero también se tomaron medidas para evitar que faltaran sin causa justificada al servicio de la catedral: cuando los beneficiados se ausentaban de la ciudad por ir a romerías, si querían que fueran contados en su prebenda, debian jurar que acudían por devoción, señalándoles el cabildo el tiempo máximo que deberian emplear en el camino de ida y vuelta y en la permanencia en el sitio donde se celebrara la romería; si cumplían esas condiciones, podrían ser contados en sus prebendas, excepto en aquellos casos que ya hemos indicado que sólo las percibían los presentes. Los beneficiados podian irse a vivir fuera de la ciudad de Ávila en periodos de pestilencia todo el tiempo que durara la misma, haciéndolo saber al presidente del coro, siendo contados en sus prebendas, siempre que no se fueran a vivir a un lugar que estuviera a más de diez leguas de la ciudad ${ }^{65}$. Y si querían asistir a misas nuevas, bodas, honras y entierros establecieron y ordenaron que, si no eran familiares del beneficiado, no pudieran ir sin ser descontados, excepto que el cabildo estableciera la conveniencia de la asistencia en razón de la calidad e importancia de la persona a quien hubiera que honrar ${ }^{66}$.

59 Ibidem, doc. núm. 95, págs.193-215.

60 Ibidem, doc. núm. 31 pág. 118.

61 lbidem, doc. núm. 118, págs. 241-243.

62. Ibidem, doc. núm. 121, págs. 247-248.

Ibidem, doc núm. 81, págs. 164-166

${ }^{54} \mathrm{lbidem}$, doc. núm. 89, pág. 181.

${ }^{65}$ Ibidem, docs. núm. 97 y 98 , págs. 216-218.

66 lbidem, doc. núm. 43, págs. 111-112 
8. Otros repartos especiales a los beneficiados. Otros repartos que se hacian a los beneficiados, además de los residuos ${ }^{67}$, eran los siguientes: repartos de besugos en la Navidad y de terneras en verano, correspondiendo a cada prebenda dos besugos y una ternera; y honorarios por asistir a entierros en la catedral o fuera de ella: los mayores ingresos los tenian cuando los familiares pedian que saliera el cabildo procesionalmente a encomendar al difunto o a enterrarle o decirle vigilia, en que, por cada vez que salieran de la iglesia mayor, recibían 8.000 maravedíes, además del pago al campanero de cinco reales de plata y los alimentos que de costumbre recibia (pan, vino, carne y pescado) ${ }^{68}$.

67 Los residuos era lo que sobraba cada año de las rentas de la mesa capitular, incluido los sueldos y salarios de los prebendados que no estuvieran presentes o de los beneficios que no se habian adjudicado. Se repartian proporcionalmente al salario de los presentes y lo que tuviera ganado cada uno de aniversarios y asistencias a los oficios de la catedral. El importe de estos residuos, como hemos visto, podía ascender a cantidades muy elevadas.

68 lbidem, doc. núm. 103, págs. 223-225. 